\title{
GO SAFE: Rapid Intelligent System for Women and Child Safety
}

\author{
K.Gopal $\operatorname{Ram}^{1} \&$ Y.Akshal Jasmine ${ }^{2}$ \\ ${ }^{\text {I} A s s i s t a n t ~ P r o f e s s o r, ~ D e p a r t m e n t ~ o f ~ E l e c t r o n i c s ~ \& ~ C o m m u n i c a t i o n ~ E n g i n e e r i n g, ~ S t e l l a ~ M a r y ' s ~ C o l l e g e ~ o f ~ E n g i n e e r i n g, ~}$ \\ Kanyakumari, Tamilnadu, India. \\ ${ }^{2} U G$ Student, Department of Electronics \& Communication Engineering, Stella Mary's College of Engineering, Kanyakumari, \\ Tamilnadu, India.
}

DOI: 10.38177/ajast.2020.4304

\section{ABSTRACT}

This paper regards about the safety system for children and women that allows instant reactions in any molestation and intimidation in public places societies and in anywhere. All around the globe women are experiencing immoral physical abuses and Children also being accused of harassment in social event or outside the home. Our project resolves both the complications. This movable device which will have a pressure switch. When the attacker is ready to assailing the women/child or at the point when they detects any uncertainty from a more bizarre, women or child would then be able to squeeze the gadget by pressing or compacting it. In a split second the pressure sensor detects this pressure and a customary SMS, with the casualty's area will be sent to their folks/parents/guardian mobile phone numbers put away in the gadget while buying it, trailed by a call. On the off chance that the call is unanswered for a drawn out time, a call will be diverted to the police and a similar message will be sent. The fundamental element of our framework is less reaction time will be required for helping the victim.

Keywords: Women safety, Child safety, Pressure switch, Safety system.

\section{Introduction}

The crime against kids and ladies are expanding exponentially day by day. They are under the danger of effectively being abducted. In present day India, ladies keep on confronting social difficulties and are regularly casualties of misuse, rough violations and provocation [1],[6]. Simultaneously kids' security has consistently been a need issue whose arrangement should continually be improved. Since the forecast of such event is beyond the realm of imagination henceforth to limit the chance of physical savagery (theft, rape and so on.) by keeping all the assist instruments with preparing to securely escape from brutal circumstance. This lessens chance and brings help when required [2],[8]. This project enters around a security framework that is planned exclusively to effectively provide security and wellbeing to ladies/kids with goal that they never feel vulnerable while opposing social difficulties.

\section{Existing Systems}

\section{A. Smart Security System for girls}

This method intended for giving security to ladies in the general public with the goal that they never face physical provocation. The framework is structured by GSM shield (SIM 900A), alert (APR 9600), GPS, ATMega328 Board, power supply unit and weight sensors [3].

\section{B. Mobile based Women Safety Application}

Numerous android based applications have been produced for ladies security in the social orders for giving crisis help. A few of them are VithU application, iGOSafely application, Stun firearm application and so forth [4].

\section{RFID -GSM imparted school children security system}

The principle point of this framework to give well-being to class youngsters. In this framework sensors like obstacle and range identification are set on the front surface of the transport so that impact ought to be kept away 
from on street. Every student is having one of a kind id. Two counters are utilized in this framework, one at section point and another at leave point. Wireless communication technology is utilized to notify the guardians and staff with respect to the status of transport [5].

\section{Society Harnessing}

This is an electronic circuit which is having an intensity of creating $3800 \mathrm{kv}$ current for help the casualty to get away. It can likewise send various kinds of 82 stuns if there should be an occurrence of different assault. The client isn't influenced on the grounds that texture utilized is bilayer. It can likewise send crisis messages to family members and guardians of casualty [3],[11].

\section{Proposed System}

To resolve the security issue concerning ladies and youngsters, we have thought of a successful thought, keeping all the shortcomings in thinking. So the framework to be structured is along these lines: A versatile gadget which will have a pressure switch.

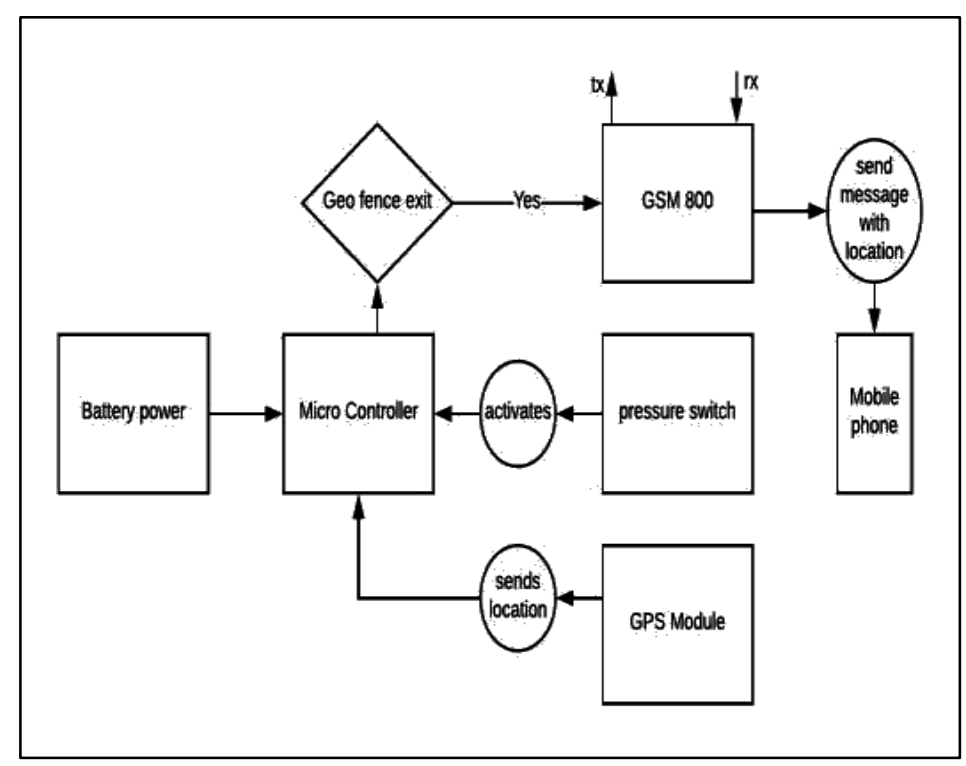

Fig.1. Women and Child Safety System Block Diagram

When an aggressor is going to assault the individual or when the individual detects any weakness from a more bizarre, he/she would then be able to squeeze the gadget by pressing or packing it. Right away the pressure sensor detects this pressure and a regular SMS, with the casualty's area will be sent to their folks/watchmen mobile phone numbers set aside in the gadget while buying it, trailed by a call. In the event that the call is unanswered for a delayed time, a call will be diverted to the police and a similar message will be sent. Also if the individual crosses some territory which is normally not gotten to by the individual then a message with the continuous area is sent to the parent/guardian's mobile phone by means of ordinary SMS.

\section{A. GSM800}

This GSM Modem can acknowledge SIM card of any GSM network administrator and act simply like a mobile phone. That portable is having specific telephone number. Benefit utilizing this modem will be that we can utilize 
its RS232 port to convey and create embedded applications. Utilizing this innovation Applications like message Control, data transfer, remote control and logging can be progress without any problem.

GSM/GPRS MODEM is a class of remote MODEM gadgets that are intended for communication of a PC with the GSM and GPRS network. It needs a SIM (Subscriber Identity Module) card simply like cell phones to actuate correspondence with the system. Additionally they have IMEI (International Mobile Equipment Identity) number like cell phones for their ID [9]. A GSM MODEM can function the accompanying activities:

- Making, Receiving, or dismissing a voice call.

- Adding, reading and looking through phonebook sections of the SIM.

- Sending, accepting and erasing of messages.

\section{B. Microcontroller Arduino}

It's an open-source electronic platform based on easy-to-use hardware and software which is having a basic microcontroller board, and an improvement domain where we can compose code for the board. Microcontroller arduino can be utilized to create interactive objects, taking input from different kind of switches or sensors, and controlling different kind of motors, lights, physical yields. In our framework we used Arduino UNO microcontroller [13].

\section{Pressure Switch}

A pressure switch is a form of switch that closes an electrical contact when a specific set liquid weight has been reached on its info. The switch might be intended to reach either on pressure rise or on pressure fall. In our framework we have utilized SPD005G part for working of pressure switch.

\section{GPS}

The GPS framework contains a group of satellites that circle the earth in a geo simultaneous way. The term GPS represents global positioning system. In preference to decide an area on the world's surface, least three satellites are required. The elements of these satellites are to precisely triangulate the specific position dependent on the scope longitude and latitude lines [7][10]. Not only giving the area of a GPS beneficiary on the world's surface, GPS likewise gives different boundaries, for example, height, speed, course, number of satellites imparting, etc. GPS is a numerous - satellite based radio situating framework in which every GPS satellite transmits information that permits client to absolutely quantify the separation between the satellites and reception apparatus to process position, speed and time boundaries to serious extent of precision. GPS conveys with high sensitivity and precision with low power utilization.

\section{Methodology}

Step-1: Pressure Switch is enacted by intersection the limit esteem which incites the microcontroller. Step-2: Microcontroller then records the area utilizing GPS module and alongside some other required boundaries gives it to the GSM module. 


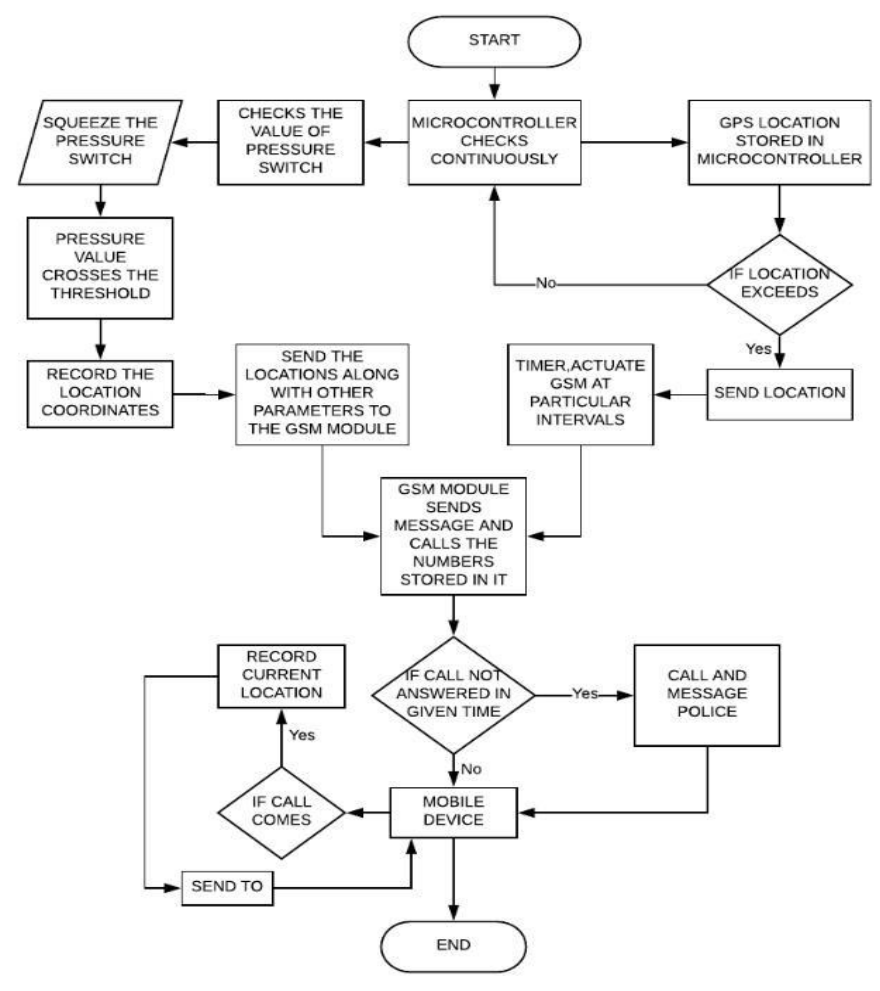

Fig.2. Women and Child Safety System Process Flow Chart

Step-3: GSM module sends the messages to the phone numbers stored in the SIM with the area following a call to those contact numbers for quite a while openings

Step-4: If the call isn't replied by them, it will be diverted to the police.

Stage-5: A geo-fence is made in the first place by determining the directions of the area. In the event that the individual crosses the geo-fencing, the gadget will send notice to the mobile phone number at specific spans.

Stage-6: If the parent/guardian calls to the gadget then the gadget will send the casualty's area to the parent.

\section{Advantages and Applications}

\section{A. Merits of proposed System}

- Less reaction time will be required for helping the person in question.

- Parents/guardians will be told when they leave safe zone set by them.

- Call will be diverted to police, if guardians can't pick the call.

- Parents/Guardians can get the area of casualty at whatever point required.

\section{B. Application of proposed System}

○ Can be utilized for the wellbeing of ladies in the public arena.

○ Can be utilized for the wellbeing of kids.

○ Can be utilized for the wellbeing of older matured individuals. 
○ Can be utilized as a lawful proof of wrongdoing with precise area data for arraignment.

○ Can be utilized for the wellbeing of genuinely tested individuals.

\section{Result}

At the point when the pressure switch is actuated, the buzzer turns on and discovers the GPS area of casualty then it will deliver notification to the parent/guardian expressing Emergency message from the name of the victim, with location. After this, It will scan for the GPS area for at regular intervals of 10 seconds until it discovers it. Up to that point at consistently it communicates something specific without area.

On the off chance that the Location is discovered it will deliver notification to the parent/guardian expressing I'm in trouble please come urgently, along the location with area diverting to Google map guides and this will happen at regular intervals of 30 seconds.

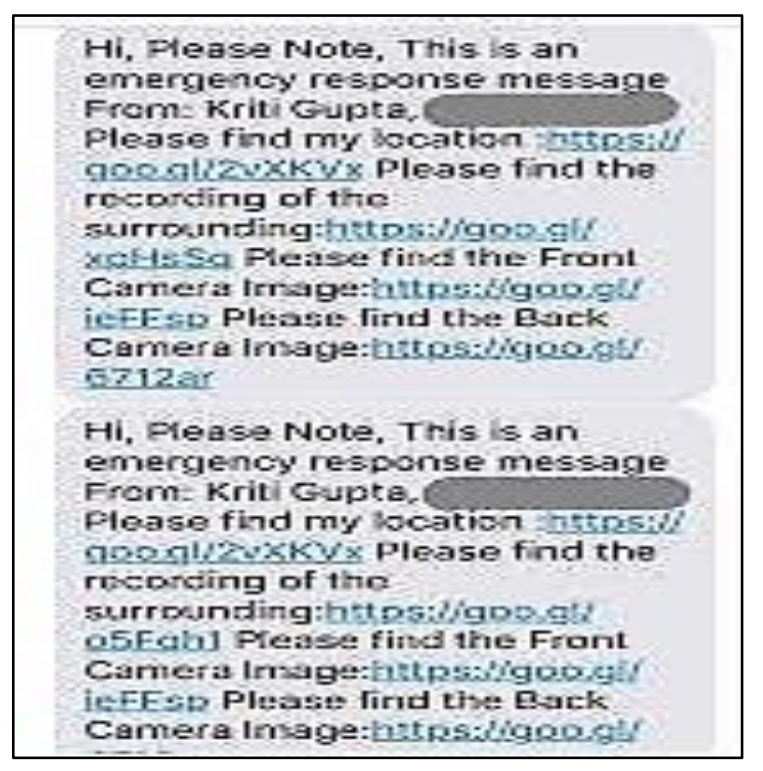

Fig.3. Describe the location and message to parents.

I am in trouble please
come urgently!!!
If you send the Text
Message (sms):
Sos
My phone will switch on
enabling you to listen
in.Please refrain from
speaking!!!
My Location Is :
http://maps.google.com/
maps?q=loc:32.1222864,3
4.898253

Fig.4. Screenshots of continuous sending message with location 
Asian Journal of Applied Science and Technology

Volume 4, Issue 3, Pages 23-28, July-September 2020

\section{Conclusion and Future Scope}

This paper review about the current wellbeing application for ladies and kids and comes out with the thought for making safe condition for ladies and youngsters in the general public, and permits them to go anyplace without any fear. What's more, it helps diminishing the crime percentage against the ladies and kids.

Our Future Scope incorporates the constant execution of the proposed framework in little size with the extra parts heartbeat sensor for observing the heartbeat of ladies and youngsters in consistently by estimating variety in blood volume in tissues and examination of different boundaries identified with heart beat for individual ladies and kids.

\section{References}

[1] Hebbar, Reshma\& A, Anisha\&Hashiya, Balkis\& L, Chaithra\&Kauser, Famiya, "Suraksha Women Safety Device and Application", International Journal of Innovative Research In Electrical, Electronics, Instrumentation and Control Engineering ( IJIREEICE), Vol 5, Issue 2, May 2017, pp. 252-255.

[2] Chand, Dhruv and Nayak, Sunil and Bhat, Karthik and Parikh, Shivani and Singh, Yuvraj and Kamath, Amita, “A mobile application for Women's Safety: WoSApp", TENCON (2015.7373171) pp. 1-5, November 2015.

[3] Prof.BasavarajChougula, ArchanaNaik, Monika Monu, PriyaPatil and Priyanka Das, "Smart Girl Security System", International Journal of Application or Innovation in Engineering \& Management (IJAIEM), Vol 3, Issue 4, April 2014.

[4] Poonam Bhilare, AkshayMohite, DhanashriKamble, SwapnilMakode and RasikaKahane, "Women Employee Security System using GPS And GSM Based Vehicle Tracking", International Journal for Research in Emerging Science and Technology, Vol-2, Issue-1, Jan-2015.

[5] K. Vidyasagar, G.Balaji, K.Narendra Reddy, "RFID-GSM imparted School children Security System", Communications on Applied Electronics (CAE) - ISSN : 2394-4714 Foundation of Computer Science FCS, New York, USA Vol 2, No.2, June 2015.

[6] Mate, Gitanjali and Gahire, Sumit and Mane, Rameshwar and Sharma, Abhay and Waghmare, Ravikiran, "Human Tracing using Location based System", International Journal of Advanced Research in Electrical, Electronics, Instrumentation and Control Engineering (IJARCCE), Vol 6, Issue 3, Jan 2017.

[7] B.Vijaylashmi, Renuka.S, Pooja Chennur, Sharangowda.Patil "Self Defense System for Women Safety with Location tracking and SMS alerting through GSM Network", International Journal of Research in Engineering and Technology ( IJRET), Vol 4, Special Issue 5, May 2015.

[8] R.A.Mahajan, SayaliA.Lavhate, SayaleeP.Waghmare, PreranaK.Pingale, "A Survey on Women's Security System Using GPS and GSM", International Journal of Innovative Research in Computer and Communication Engineering, Vol 5, Issue 2, February 2017.

[9] Francis Enejo Idachaba, "Design of a GPS/GSM based tracker for the location of stolen items and kidnapped or missing persons in Nigeria", ARPN Journal of Engineering and Applied Sciences, Vol 6, No. 10, October 2011.

[10] Ibrahim Abdallah Hag Eltoum, Mohammed Bouhorma, "Velocity based Tracking and Localization System using Smartphones with GPS and GPRS/3G", International Journal of Computer Applications (0975 - 8887) Vol 76, No.11, August 2013.

[11] Ghaith Bader Al-Suwaidi, Mohamed Jamal Zemerly, "Locating friends and family using mobile phones with global positioning system (GPS)," IEEE/ACS International Conference on Computer Systems and Applications, 2009.

[12] Anwaar Al-Lawati, Shaikha Al Jahdhami, Asma Al-Belushi, Dalal Al-Adawi, MedhatAwadalla and Dawood Al-Abri, "RFID-based System for School Children Transportation Safety Enhancement", 8th IEEE GCC Conference and Exhibition, Muscat, Oman, 1-4 February, 2015.

[13] Songphon Namkhun, Daranee Hormdee "Two-Way Semi-Offline Location Tracking and Control System via GSM" ITC-CSCC 2011, June 19-22, 2011, Gyeongju, Korea. 